\title{
Imagens patógenas: subsídios para estudos de transtornos de imagens a partir do caso clínico e do método Warburg
}

\section{Pathogenic images: support for studies of image disorders based on the clinical case and the Warburg method}

\author{
Norval Baitello Jr. ${ }^{1}$ \\ Rodrigo Daniel Sanches ${ }^{2}$
}

\begin{abstract}
Resumo: Partindo do caso clínico de Aby Warburg, a proposta do artigo é apresentar subsídios para uma leitura da imagem como pharmakon. Para tanto, mobilizamos conceitos fundantes da Ciência da Cultura proposta por Warburg, como a sua teoria da imagem e seu método, que rejeitam toda tentativa "exclusivamente estetizante" de compreensão da visualidade e da imagem. O método warburguiano pressupõe a capacidade das imagens de impactar, capturar e transformar olhares gerando ambientes. Como esse ambiente possui a potência de um pharmakon, analisamos um exemplo que corrobora com o diagnóstico de Warburg sobre a potencialidade das imagens: a estratégia da indústria do tabaco, através da atuação do esportista brasileiro Ayrton Senna, ancorada em uma indústria das imagens.

Palavras-chave: Imagem como pharmakon; método Warburg; Transtornos de imagens; indústria tabagista.
\end{abstract}
Abstract: Based on the clinical case of Aby Warburg, the proposal of this article is to present support for a reading of the image as a pharmakon. As such, we have utilized fundamental concepts from the Science of Culture proposed by
1 Pontifícia Universidade Católica de São Paulo (PUC-SP). São Paulo, SP, Brasil. https://orcid.org/0000-0001-7814-7633 E-mail: norvalbaitello@pucsp.br
2 Faculdade Cásper Líbero (FCL). São Paulo, SP, Brasil.
https://orcid.org/0000-0003-3433-0916 E-mail: rodrigo.dsa@gmail.com 
Warburg, such as his image theory and his method, which reject any "exclusively aestheticizing" attempt to understand visuality and images. The Warburg method presupposes the capacity of images to impact, capture and transform views by generating environments. As this environment bears the potency of a pharmakon, we have analyzed an current example that corroborate Warburg's diagnosis of the potentiality of images: the strategy of the tobacco industries, through the performance of Brazilian sportsman Ayrton Senna, anchored in an image industry.

Keywords: Image as pharmakon; Warburg method; image disorders; tobacco industries. 


\section{Introdução: mentes assombradas ${ }^{3}$}

Toda a humanidade é - o tempo todo e para sempre - esquizofrênica. Aby Warburg (2015

Em sua carreira de médico e escritor, uma das inquietações de Oliver Sacks foram as alucinações e os delírios. Ele abordou esses sintomas em diversas obras, como "O homem que confundiu sua mulher com um chapéu", "Vendo Vozes", "Alucinações musicais" e "A mente assombrada”. Nesta última, Sacks (2013, p. 12) argumenta que as alucinações "sempre tiveram um lugar importante em nossa vida mental e em nossa cultura”. Devemos nos questionar, diz Sacks (2013, p. 12), "em que medida experiências alucinatórias ensejaram nossa arte, folclore e até religião". Teria faltado nesta pequena e abrangente lista tríplice de Sacks o tópico "ciência"?

Sacks via "A mente assombrada" como uma espécie de antologia das alucinações, descrevendo experiências e o impacto delas sobre os indivíduos que as sofrem, pois acreditava que o poder das alucinações só poderia ser entendido a partir dos relatos em primeira pessoa. As causas dos delírios e alucinações são muitas e, em certos casos, estimuladas por estados emocionais como, por exemplo, terror, horror, angústia ou apreensão de acontecimentos traumáticos que ameaçam a vida (Sacks, 2013).

A história da humanidade é pródiga em eventos traumáticos que abarcaram centenas de milhares de pessoas, deixando sequelas físicas e emocionais incomensuráveis. Duas delas, certamente, são a Primeira e a Segunda Guerra Mundial. Em relação à Primeira Guerra, Sacks observa que

3 Este trabalho contou com a colaboração da médica psiquiatra e professora Maristela Schaufelberger Spanghero, doutora pelo Departamento de Psiquiatria da Faculdade de Medicina da Universidade de São Paulo (FMUSP). 
Alguns médicos supuseram que devia existir um distúrbio orgânico no cérebro responsável pelo que, na época, se chamava de neuroses de guerra: elas pareciam diferir em vários aspectos das neuroses "normais". O termo "shell shock" [traumatismo causado pelo ruído de explosão de granadas] foi cunhado com base na ideia de que o cérebro daqueles soldados havia sido mecanicamente desarranjado pelos repetidos abalos das granadas altamente explosivas introduzidas nessa guerra. Até então não existia o reconhecimento formal dos efeitos retardados do severo trauma para os soldados, submetidos por dias a explosões de granada e gás de mostarda, em trincheiras lamacentas abarrotadas com cadáveres putrefatos de seus companheiros (SACKS, 2013, p. 217-218).

Ainda em relação às guerras e conflitos, há também a alucinação dos "membros fantasmas", quando soldados perdem partes do corpo mas continuam a sentir dor, cócegas ou outras sensações na parte perdida ou amputada em decorrência dos ferimentos das batalhas. As guerras, portanto, são eventos capazes de gerar estados emocionais extremos, causando alucinações que podem, segundo Sacks (2013), acometer comunidades inteiras.

Mas se a guerra é traumática para aqueles que estão envolvidos diretamente no front, e também para aqueles que residem nas áreas de conflito ou são diretamente afetados pelos confrontos, será que as imagens dessas mesmas guerras teriam a capacidade de causar adoecimento? Seriam as imagens de guerra (ou, ampliando um pouco seu universo, as imagens de grandes catástrofes) patogênicas?

\section{A mente de Aby Warburg}

Criador da impressionante Biblioteca Warburg de Ciências da Cultura (Kulturwissenschaftliche Bibliothek Warburg - KBW), Aby Warburg (1866-1929) deixou uma herança notável em livros, atualmente alocados no Warburg Institute, na Universidade de Londres. Depois de sua formação em História, História da Arte, Arqueologia e História das Religiões da Antiguidade, o jovem Aby Warburg começou, em 1889, a reunir o acervo que se transformaria na sua famosa Biblioteca, em 
Hamburgo (Alemanha). É inegável o protagonismo da Biblioteca na história de vida de Warburg, sua concepção, sua organização, seus objetos principais e sua vocação. Tudo isto a transforma em local único de pesquisa sobre muitos temas da cultura humana e mesmo em objeto ímpar como concepção de cultura, uma vez que ele próprio se absteve de nomear a ciência que estava inaugurando juntamente com a Biblioteca. Robert Klein a denomina "ciência sem nome", denominação acatada por Giorgio Agamben (KLEIN, 1970).

Verdade é que o pensamento próprio e inovador de Warburg, que pautou a KWB, foi eclipsado pela mesma por quase 100 anos. E apenas nos anos 2000 começou a ser desvendado e levado a sério pela pesquisa científica ${ }^{4}$. Mesmo assim ainda hoje é objeto de muita polêmica e apropriações questionáveis. Não se tratava, porém, de uma biblioteca e um acervo sobre a história da arte ou das imagens, mas do que ele denominou "uma coleção de registros para a psicologia do estudo da expressão humana” (WARBURG, 2015, p. 71). Para o estudioso, "graças ao uso de categorias de desenvolvimento gerais e insatisfatórias, a história da arte tem sido até aqui impedida de pôr seu material à disposição da 'psicologia histórica da expressão humana', que ainda, é verdade, espera por ser escrita" (WARBURG, 2015, p. 127). Suas reflexões aproximaram objetos separados pelas grades e fronteiras do tempo, com estudos sobre a Vênus de Botticelli, os rituais das aldeias dos índios Hopi, no Novo México (Estados Unidos), e sobre os desenhos de suas crianças. "Alargando os limites de manifestações da imagem para muito além do universo artístico, Aby Warburg a entende como o mais importante recurso de vinculação, como mídia” (BAITELLO, 2010, p. 61).

Em seus últimos anos de vida, Warburg trabalhou no projeto de um grande atlas das imagens, Mnemosine, mapeando famílias de imagens e seus étimos, ilustrando sua presença em diferentes épocas ou distintos

4 Apenas em 2010 foi publicada uma reunião da obra de Warburg em uma edição cuidadosa e confiável. Destaque-se aqui também o trabalho crítico de Claudia Wedepohl, atual diretora do Arquivo Warburg, participante da edição dos Gesammelte Schriften (Escritos Reunidos) (WARBURG, 2015). 
ambientes, além de demonstrar seu potencial de sentido e sua força expressiva em diferentes épocas e contextos.

Aby Warburg sofreu um colapso emocional em novembro de 1918. Após as primeiras internações em Hamburgo (com o Dr. Heinrich Georg Embden, de 2/11/1918 a 17/07/1919) e Jena (de 9/10/1920 a 15/04/1921 sob os cuidados do Prof. Dr. Hans Berger), foi transferido, finalmente, em 1921, para a clínica Bellevue, em Kreuzlingen, Suíça, dirigida por Ludwig Binswanger, criador da terapia existencial, discípulo e amigo de Sigmund Freud 5 . Foram quase seis anos sendo acometido por surtos e visões, comportando-se com rebeldia; era ruidoso, esbravejava, tinha surtos de fúria e visões persecutórias a ele próprio e a sua família, acusando os médicos e enfermeiros de envenená-lo.

Warburg teve alta em 1924 depois de demonstrar sua sanidade ao ministrar uma conferência para os médicos e pacientes da clínica sobre uma expedição exploratória fotográfica que fizera em 1895 aos índios Hopi no Novo México, Estados Unidos. A conferência, emblemática em muitos aspectos, somente foi publicada em $1949^{6}$, vinte anos após a morte de Warburg, pelo Warburg Institute de Londres, com repercussão pífia; os tempos eram de difícil reconstrução. E hoje sabe-se que a versão publicada por Saxl foi amplamente copidescada, conferindo fluidez às notas soltas de Warburg sobre as imagens dos índios Pueblo. Mesmo assim, o escrito Schlangenritual Ein Reisebericht ( $\mathrm{O}$ ritual da serpente: Um relato de viagem) somente ganhou edição alemã em 1988 e traduções para outras línguas nos anos subsequentes. As anotações originais não copidescadas foram publicadas apenas em 2010 em Werke (Obras) (WARBURG, 20107).

5 No dia 8 de novembro de 1921 Binswanger responde a Freud que perguntara sobre o estado clinico do "famoso professor", afirmando desesperança sobre um prognóstico positivo (FICHTNER, 1992, p. 176).

6 Terminada a apresentação da conferência na Clínica Bellevue, em 23 de abril de 1923, Warburg reúne suas anotações e o material dos diapositivos e os envia a Fritz Saxl, na direção de sua biblioteca em Hamburg, com a ordem explícita de não publicar em hipótese alguma, nem permitir o acesso às anotações a ninguém, com exceção de seu amigo Prof. Ernst Cassirer.

7 A tradução de alguns textos em português em Histórias de fantasmas para gente grande parte desta edição alemã. 
O caso clínico tem recebido crescente atenção não apenas por sua indiscutível natureza polêmica do ponto de vista médico e psicológico, com mudanças de diagnóstico e prognóstico, mas também por ser uma enfermidade de imagens, com imagens, por imagens, de cenários sombrios que se tornariam dura realidade pouco mais de uma década depois (conforme BAITELLO, 2017).

\section{As imagens podem causar adoecimento? 0 horror das/pelas imagens (a coleção de fotos de guerra de Warburg)}

O adoecimento de Warburg é sem dúvida um caso complexo - não é possível agora fazer uma anamnese, com um século de distância dos fatos. Há, contudo, ainda distintas tomadas de posição a respeito, ao longo do século XX. Enquanto o Sir Ernst Gombrich, autor da primeira biografia de Warburg e afamado diretor do Warburg Institute em Londres por décadas, silencia totalmente o episódio clínico, o jovem discípulo Carl Georg Heise expressa indignação sobre o flagrante erro de diagnóstico de Binswanger (seguindo Berger) e reclama que a questão tenha ficado encoberta pelo silêncio. É preciso ressaltar que se trata do início do século XX, e não havia ainda os antipsicóticos de primeira e segunda geração; bem como obviamente não havia estudos e pesquisas de neuroimagem estrutural e funcional, que nos últimos 40 a 50 anos "identificaram alterações cerebrais significativas nas psicoses, sobretudo na esquizofrenia” (DALGALARRONDO, 2010, p. 384).

A recuperação de Warburg começa com a mudança de diagnóstico feita por Kraepelin em 6 de fevereiro de 1923, incumbido pela família Warburg de fazer uma avaliação do caso. Emil Kraepelin ${ }^{8}$ (1856-1926),

8 Em "Madness: a brief history", Roy Porter (2002) sublinha a importância de Kraepelin nos estudos dos transtornos mentais: "Emil Kraepelin (1856-1926) it was essential to shed the unscientific dross wich had gathered around psychiatry. Following an early appointment at Dorpat University (in Estonia, then in Prussia), Kraepelin became professor at the university clinic at Heidelberg, a principal center of German medicine. His career marks the culmination of a century of descriptive clinical psychiatry and psychiatry nosology. (...) The course of psychiatric illness, he insisted, offered the best clue to its nature, rather than, as in common practice, the raft 
considerado o mais importante psiquiatra daquele tempo, foi convidado pela família a analisar o caso e o paciente, com a anuência de Binswanger.

O diagnóstico então formulado por ele divergia daquele anterior, conforme descrito na obra "La guérison infinie: Histoire clinique d'Aby Warburg":

Provoquée par la famille, l'apparition de Kraepelin équivaut sans le moindre doute à une déclaration de méfiance, au moins temporaite, à l'égard des métodos adoptées par Binswanger. Le diagnostic avait été jusque-là, de manière irrévocable, celui de schizophrénie. C'est ainsi que Warburg avait été étiqueté dans son dossier médical à son arrivée à Kreuzlinge. Le diagnostic de Kraepelin est em revanche: "état mixte maníaco-dépressif"; le pronostic, que inverse les termes de celui de Berger de manière si littérale qu'il en semble la parodie intentionelle, laisse finalement entrer um rayon de lumière dans la chambre noire du futur de Warburg: avec un pronostic absolument favorable, même si Kraepelin ne préconise pas que Warburg puisse quitter la clinique précisément parce qu'il s'agit d'un cas difficile et qu'une sortie precoce ne ferait que ralentir le processus de sa guérison (WARBURG; BINSWANGER, 2007, p. 14-15).

Retomemos a questão: as imagens de tragédias como as guerras teriam a capacidade de causar adoecimento? Seriam as imagens patogênicas? Qual a relação entre o adoecimento de Warburg, sua internação, e imagens de guerra? Em 2004 foi encontrada no Arquivo do Instituto Warburg, em Londres, uma coleção de fotografias da Primeira Guerra Mundial compilada pelo seu fundador. Sobre as três caixas contendo 1547 imagens $^{9}$ relacionadas à Primeira Guerra Mundial, das quais a imensa maioria são fotografias jornalísticas, Leão Serva (2017) analisa que elas estariam em consonância com as preocupações manifestadas por Warburg em suas reflexões, especialmente em duas frentes. A primeira delas

of symptoms the patient showed at a particular moment. On this basis, Kraepelin wrought a great innovation in disease concepts and classification" (PORTER, 2002, p. 184)

9 A coleção encontrada é remanescente de um total de 5000 fotos. Na intempestiva transferência clandestina da biblioteca de Hamburgo para Londres em 1933, perderam-se muitos materiais que tiveram que permanecer em Hamburgo. 
É a preocupação com a questão judaica. Durante a Primeira Guerra, Warburg pareceu pressentir os ventos do antissemitismo que marcariam a vida alemã sob o domínio nazista. Naquele momento, curiosamente, havia uma inversão de papeis: os judeus eram perseguidos formal e informalmente nas regiões vizinhas do Império alemão, sob domínio russo: Polônia, Ucrânia, Galízia, Belarus. Nessas áreas, os soldados alemães frequentemente eram saudados como libertadores e a ocupação autorizava os judeus a formarem grandes filas a espera de vistos para migrarem para a Alemanha, onde as comunidades eram integradas e respeitadas (SERVA, 2017, p. 4).

O segundo componente presente nas imagens de guerra colecionadas por Warburg é

A recorrência, na coleção de fotos, de imagens de submarinos, balões e aviões militares, novidades tecnológicas da virada do século 19 para o 20 que naquele conflito mundial foram introduzidas no âmbito das guerras. Antes da guerra, em 1913, Warburg havia produzido um pequeno ensaio chamado "Aeronave e Submergível no Imaginário Medieval" (WARBURG, 2013, 313 e segs.), que mostra que, antes de existirem como equipamentos reais produzidos pela tecnologia do final do século 19 ou começo do 20, essas máquinas eram imaginadas e, possivelmente desejadas pelos homens; ou poderíamos dizer, ao contrário, que elas foram criadas para atender a uma já antiga demanda da cultura humana (SERVA, 2017, p. 5).

Os turbulentos anos da Primeira Guerra Mundial e a década seguinte já incubavam os sombrios tempos dos trintas e quarentas. Sem dúvida o cenário histórico, político e cultural contribuiu para a profunda e dramática doença mental de Aby Warburg - um distúrbio das imagens que o ameaçavam, a ele e a sua família (BAITELLO, 2017). As imagens, para Warburg, não eram apenas artísticas ou estéticas, mas possuíam uma força intrínseca, uma potência geradora de sentidos, de ações internas e externas, uma força criadora de ambientes e ambientalidades ${ }^{10}$. Pensando a imagem não apenas pela sua vertente estética, mas principalmente

10 O conceito de "ambientalidade" é usado aqui segundo Watsuji, Tetsuro (Antropologia del paisaje. Salamanca: Sigueme, 2006). 
levando em conta sua potência relacional, "a imagem não é apenas produto, ela também é produtora, possui uma existência ambivalente, é criadora e criatura de um entorno" (BAITELLO, 2017, p. 35).

Nesse sentido, as imagens de guerra colecionadas por Warburg potencializavam o horror daquele período. $\mathrm{O}$ apavoramento apresentado naquelas fotografias (em sua maioria jornalísticas) estava ocorrendo num entorno imediatamente próximo a ele e sua família. Seguramente haverá na história do homem outros ambientes criados por imagens catastróficas. A história do medo, desenvolvida por Jean Delumeau, não seria outra coisa senão a história do poder de imagens aterradoras? Seria o caso clínico de Warburg um exemplo análogo às enfermidades e aos distúrbios de imagem geradores de patologias somáticas contemporâneas?

O jornalista, ex-repórter de guerra e estudioso de Warburg, Leão Serva (2017) aponta que há um conjunto de indícios do relacionamento passional e visceral de Warburg com as fotografias de guerra; as imagens eram encomendadas e requisitadas pelo estudioso alemão ao longo dos quatro anos de duração da Primeira Guerra. Diz Serva:

Em uma primeira abordagem, é muito marcante dessa sintonia entre o autor e a coleção a recorrência, entre as fotos, de imagens de balões e aviões militares, novidades tecnológicas da virada do século 19 para o 20 que, naquele conflito mundial, foi introduzida no mundo das guerras. Imagens semelhantes viriam a marcar o "Atlas Mnemosine"ll e, de forma indireta, estão presentes também na conferência sobre o Rito da Serpente dos índios Hopi (SERVA, 2017, p. 55).

As imagens colecionadas por Warburg continham todo tipo de monstruosidade e barbárie oriundos de uma batalha. Balões explodindo em pleno ar, corpos mortos, soldados feridos ou com membros amputados, enterros, bombardeios em cidades, edifício e igrejas, e, não menos chocante, várias cenas de cavalos mortos. Se Warburg dedicou sua própria vida à vida e à pós-vida das imagens como construtoras de ambientes, como fórmula de pathos (Pathosformel, termo cunhado por Warburg), sem dúvida o cenário histórico, político e cultural dos anos 1910-1920 contribuíram para a sua profunda e dramática doença mental. As mais 
de 1500 imagens de guerra colecionadas por ele constituíam um relato brutal e perturbador de algo não distante, de outro período ou região, mas próximo, no tempo e no espaço. O cenário vivido por Warburg e presente nas imagens de guerra compunham o que Oliver Sacks denomina de atmosfera profundamente delusória, capaz de "favorecer alucinações geradas por estados emocionais extremos” (SACKS, 2013, p. 220).

\section{0 (difícil) pensamento de Warburg, sua teoria da imagem, sua "ciência sem nome", seu método}

A concepção da KBW, sua biblioteca tão zelosamente alimentada com novas aquisições e incansáveis buscas (comprovadas na volumosa correspondência com livreiros e antiquários) apresenta-se como anverso de uma moeda, cuja face oculta revela um pensamento completamente transgressor dos cânones disciplinares reinantes nos séculos XIX e XX. Não havia palavras sequer para definir os temas que Warburg elegeu como centrais para a sua "Ciência da Cultura". Por isso ele as criava, em neologismos que até hoje exigem esforço para os estudiosos. Um deles foi "Pathosformel" (fórmula de pathos) para definir as imagens. Tal conceito pretende explodir qualquer tentativa "estetizante" de compreensão da visualidade (e da imagem, em geral). Pressupõe que o objeto-imagem gera impacto sobre aqueles com os quais interage. Assim, uma imagem, sendo uma fórmula de pathos, não se define por suas características formais, senão por suas potencialidades de impactar. E tal potencialidade existe tanto mais quanto mais lastro histórico ela possui, armazenando energias de um trajeto ou percurso histórico.

Para isto Warburg criou a palavra "Nachleben", "pós-vida". Assim, toda imagem materializa uma pós-vida, evocando camadas pregressas de experiências. Um outro conceito importante nasce com o neologismo "Denkraum", "espaço-pensamento". Entre uma imagem e outra emerge um "espaço-pensamento", bem como ocorre também entre uma pessoa e uma imagem, uma força viva e pulsante. Com tantos outros conceitos 
como estes, fica implícita a tomada de posição por uma ciência não formalizante. Deste modo foge-se dos cânones de uma história da arte como história de formas tanto quanto se foge de uma iconologia pura e simples ou de uma história dos estilos. Warburg espumava de ira diante das leituras "exclusivamente estetizantes" das imagens (incluindo as artísticas), segundo seu discípulo Carl Georg Heise, declarando que tal mentalidade deve ser trancafiada dentro de um "guarda-venenos" (Giftschrank) em sua biblioteca ${ }^{11}$. "O grande espectro temático da metodologia proposta por Warburg somente pode ser o das "Ciências da Cultura”, a mesma metodologia conceitual que construiu a magistral biblioteca $^{12}$.

Um dos conceitos centrais da metodologia de Warburg era o da migração das imagens, algo que se resume na expressão criada por ele de Bilderfahrzeug (veículo de imagens). Tal migração não segue linhas de causalidade nem mesmo previsibilidade. Uma imagem pode estar presente no imaginário grego tanto quanto no imaginário dos índios Hopi ou numa tribo africana, bem como nos mitos judaico-cristãos, o que demonstra sua potência como transportadora de símbolos.

A metodologia warburguiana, que hoje vem sendo intensivamente estudada nas pesquisas vinculadas ao Warburg Institute, deve considerar o conceito de símbolo como um alicerce sólido a partir do qual a imagem deve ser estudada. Não se trata aqui, em nenhuma hipótese, de uma conceituação semiótica do símbolo, se não ancorada na obra de Friedrich Theodor Vischer. Assim é apresentado o conceito de Vischer por Lescourret:

L'image et la signification ne font qu'un: le boeuf est l'image de la force parce que le boeuf est fort. Le serpente est l'image de la pluie parce qu'il est comme l'éclair. Puis Vischer (toujours selon l'exposé de Wind) distingue le symbole <magiquement assoiatif $>$ de l'allégorie <logiquement

11 O "guarda-venenos" foi objeto de pesquisa de Norval Baitello Jr., financiada pela Fapesp, no arquivo Warburg, de novembro de 2018 à janeiro de 2019.

12 As contribuições de Warburg para uma "ciência da imagem" e, por extensão, uma "ciência da comunicação" estão brevemente descritas por Norval Baitello Jr. no verbete "Warburg, Aby (1866-1929)", presente no Dicionário de Comunicação organizado por Ciro Marcondes Filho (2009). 
dissociative $>$. Dans l ecas, l'association entre l'image et la signification requiert l'assistance d'um prêtre qui accomplit la transsubstantiation au cours d'um rituel. Em revanche, dans le second cas, l'association entre l'image et son sens est superficielle: l'image n'est pas douée des puvoirs de l'invisible qu'elle represente (LESCOURRET, 2014, p. 128-129).

O método warburguiano usado tanto nas suas conferências, no seu texto, no seu atlas quanto na construção de sua biblioteca pressupõe uma relação complexa entre os objetos, sua historicidade pregressa e sua potencialidade futura. "Impacto" seria, portanto, algo presente potencialmente em uma imagem, sua capacidade de capturar e transformar olhares gerando ambientes. Warburg se preocupava com o Denkraum (espaço de pensamento) gerado por uma imagem ou por uma família de imagens, sendo este Denkraum um tipo de atmosfera de símbolos ou um ambiente simbólico do qual participa ativamente todo aquele se apropria daquela imagem. O ambiente nunca exclui o olhador. Este ambiente possui, portanto, a potência de um "pharmakon".

\section{Imagem como "pharmakon"}

A palavra "pharmakon", em grego, significa, em sua origem, tanto substância que cura como substância que mata, tanto veneno quanto remédio. Se a lida com as dolorosas imagens de guerra contribuíram para um estado de profunda depressão com episódios alucinatórios, a busca de imagens primordiais da cultura Hopi teve papel restaurador da sobriedade? São perguntas que somos autorizados a fazer diante do arcabouço teórico proposto por Warburg. Se tal questionamento possui alguma pertinência, devemos então nos questionar a respeito da inundação de imagens nos ambientes mediáticos em que vivemos imersos dia e noite. A reflexão de Warburg nunca se ateve aos objetos imagéticos do mundo da arte, muito pelo contrário, seus objetos de análise e estudo iam desde os panfletos demonizantes aos sarcófagos, das ilustrações em livros, revistas e almanaques aos desenhos nos "cassone" (baús que abrigavam os enxovais). Há algo específico nessas imagens e nos ambientes 
que elas criam que se aproxima dos ambientes altamente contaminados de persuasão das imagens que cada vez mais invadem nossas casas e nossos corpos. $\mathrm{O}$ envenenamento por imagens se manifesta de que maneira hoje?

\section{Das imagens da guerra à guerra das imagens (a estratégia da indústria do tabaco - o caso Ayrton Senna)}

Das imagens das guerras, como as que faziam parte da coleção de Waburg, hoje experimentamos um outro tipo de guerra: a midiática. É uma "guerra das imagens", que nos assolam, interpelam, nos movem com sua sedução e capacidade de impactar. Na sua imensa maioria, tem como finalidade a tomada de uma decisão, qual seja, a compra de um produto, serviço ou ideia. Na guerra das imagens, o objetivo é vender. Nesse contexto, a publicidade moderna é um dos principais (mas não o único) sistemas comunicativos geradores de imagens, criando uma atmosfera, ambientes e ambientalidades. Não apenas na mídia tradicional, a publicidade produz e faz circular imagens e reverbera sentidos em diversas telas e plataformas, concorrendo com outras fontes de produção e circulação de enunciados, como as redes sociais (onde a publicidade se faz cada vez mais presente).

Mas como o envenenamento por imagens se manifesta hoje? Vamos trabalhar aqui com um exemplo no qual é possível visualizar o "Pathosformel", ou seja, o impacto que as imagens podem gerar sobre aqueles com as quais interage: as imagens produzidas pela indústria do tabaco. Transtornos associados ao tabaco estão presentes nas versões atuais dos sistemas classificatórios de Transtornos Mentais atuais, tanto na Classificação Internacional das Doenças (CID 10) da Organização Mundial de Saúde ${ }^{27}$ quanto na $5^{\text {a }}$. edição do Manual Diagnóstico e Estatístico dos Transtornos Mentais da Associação Psiquiátrica Americana (DSM 5)4. No DSM 5, o Transtorno por uso de Tabaco está incluído na seção "Transtornos Relacionados a Substâncias e Adicção", onde são incluídas 
as seguintes classes de substâncias com potencial aditivo: álcool, cafeína, cannabis, alucinógenos, inalantes, opioides, sedativos/hipnóticos/ansiolíticos, estimulantes (cocaína, anfetaminas e outros), tabaco e outras (ou drogas desconhecidas).

O tabagismo é considerado uma pandemia e um grave problema de saúde pública. Por conta da expansão global do tabagismo no século XX, em 2016, 20\% da população mundial fumou tabaco. No mesmo ano, existiam 1,1 bilhão de fumantes adultos em todo o planeta, número que se manteve praticamente inalterado desde $2000^{13}$. Mas como a indústria do cigarro alcançou tantos usuários? Quais suas estratégias? Como ela se engendrou no âmago de populações tão distintas cultural e geograficamente, mesmo trazendo inúmeros malefícios aos seus usuários? A indústria do tabaco se consolidou no final do século XIX e primeira metade do século XX, quando o cigarro passa a ser produzido de forma industrial e tornou-se o primeiro produto comercial globalizado, principalmente com presença maciça nos campos de batalha da I Guerra Mundial.

13 Disponível em <https://nacoesunidas.org/oms-1-em-cada-5-pessoas-no-mundo-fuma/>. 
Figura 1. Uma enfermeira da Cruz Vermelha acende cigarro de soldado ferido no hospital militar de Souilly, na França, durante a Primeira Guerra Mundial, por volta de 1917.

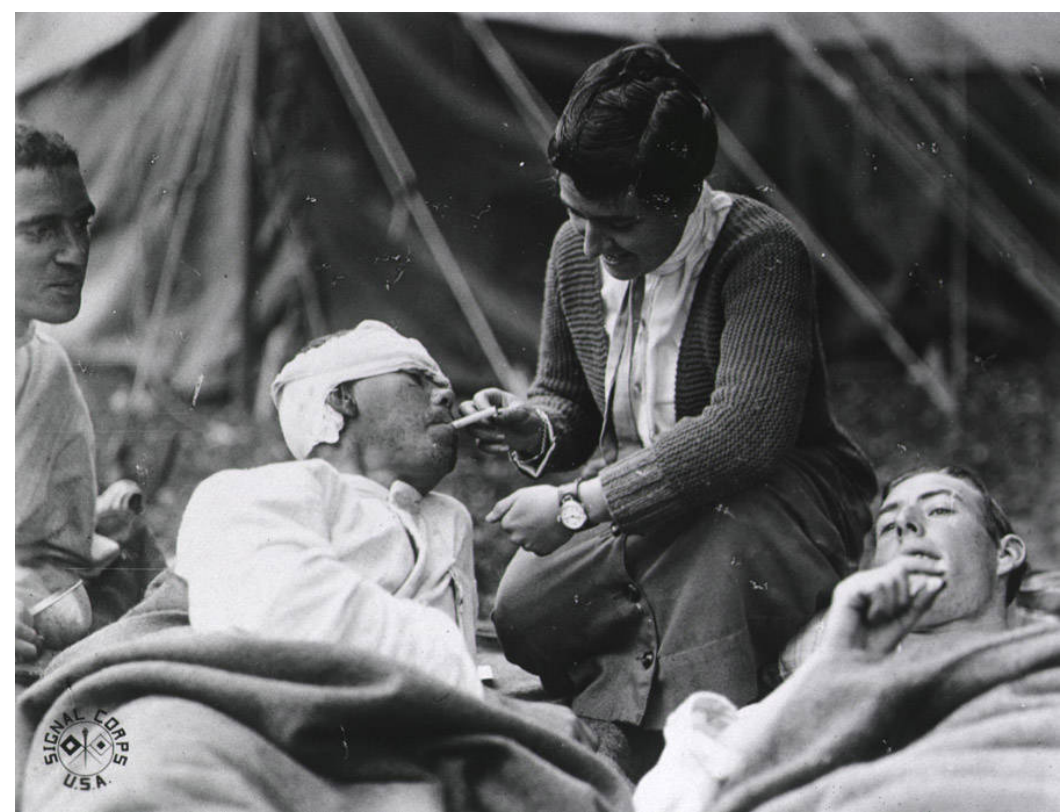

Fonte:Disponívelem: $<$ https//br.historyplay.tv/noticias/fotos-mostram-momentos-dramaticos-enfren tados-por-medicos-de-combate $>$.

Não seria possível enumerar, em um único artigo, todas as artimanhas da indústria do tabaco para vender seus produtos em escala mundial. No presente texto, vamos nos ater a uma das estratégias - o uso ostensivo das imagens atreladas ao esporte, mais especificamente ao piloto brasileiro Ayrton Senna. Mesmo em relação às campanhas publicitárias da indústria do cigarro, não seria possível, em um único momento, enumerar e analisar todas as já realizadas e veiculadas, uma vez que eram direcionadas a vários públicos e abarcavam temas diversos, desde esportes, benefícios à saúde, redução de apetite, emagrecimento, sucesso e charme, entre outros.

A indústria do tabaco sempre investiu de forma agressiva em campanhas publicitárias, fato decisivo para que o comportamento de fumar 
ganhasse uma representação social positiva, a partir da associação do uso do tabaco com ideal de autoimagem como: beleza, liberdade, sucesso. Um dos episódios mais emblemáticos foi uma estratégia do uso das imagens para promover o "direito ao fumo pelas mulheres". Em 1929, Edward Bernays, pioneiro no uso da Psicologia e Ciências Sociais para persuasão do público consumidor, arquitetou um dos grandes episódios de marketing conhecido como Torches of Freedom, quando um grupo de mulheres portando cigarros participou do Easter Sunday Parade, desfile realizado no domingo de Páscoa em Nova Iorque (Estados Unidos). O tabagismo, que até então fazia parte do universo masculino, passava para as mãos femininas como um ato simbólico que reunia rebeldia, liberdade e feminismo. O que estava por trás desse ato: um plano publicitário para expandir o consumo do tabaco tendo como público-alvo as mulheres.

Propagandeado através do cinema, televisão e como patrocinador de eventos culturais e esportivos de alcance mundial (como a Fórmula I, por exemplo), e com o uso de estratégias de marketing cada vez mais agressivas, o cigarro continuou se disseminando, inclusive entre as mulheres, e a indústria do tabaco passou a ter lucros estratosféricos.

Considerado um dos ídolos do esporte brasileiro e internacional, durante quase toda a sua carreira, Ayrton Senna, que completaria 60 anos em 2020, foi patrocinado por empresas de tabaco. Segundo o especialista em automobilismo Marcos Júnior Micheletti (2019), Senna atuou como garoto-propaganda para empresas de diferentes ramos e negócios, desde instituições bancárias, brinquedos, automóveis, combustíveis e relógios, mas a maior parte dos vencimentos do piloto vieram das empresas de tabaco. Das quatro equipes pelas quais competiu, três delas eram patrocinadas por fabricantes de cigarro. Quando estreou na Fórmula I, pela equipe Lotus, a fabricante de cigarros John Player Special veiculou em 1985 um comercial cuja mensagem final dizia: "Acelere, Ayrton! John Player Special acompanha! John Player Special, sabor e emoção!” (MICHELETTI, 2019, s/p). Ainda na Lotus, Senna seria patrocinado por outra empresa tabagista, a Camel, em 1987. Posteriormente, Senna 
correu pela equipe McLaren, exibindo, durante seis temporadas, as cores vermelha e branca da empresa de tabaco Marlboro. A Marlboro, aliás, foi uma marca presente em grandes momentos da carreira do piloto.

Em 1994, Senna trocou a Marlboro (uma das marcas da Philip Morris International, empresa multinacional produtora de tabaco e seus derivados, com produtos vendidos em mais de 180 países) pela britânica Rothmans, marca extinta em 1999.

Figura 2. Os carros pilotados por Ayrton Senna durante sua carreira, exibindo marcas de empresas de tabaco
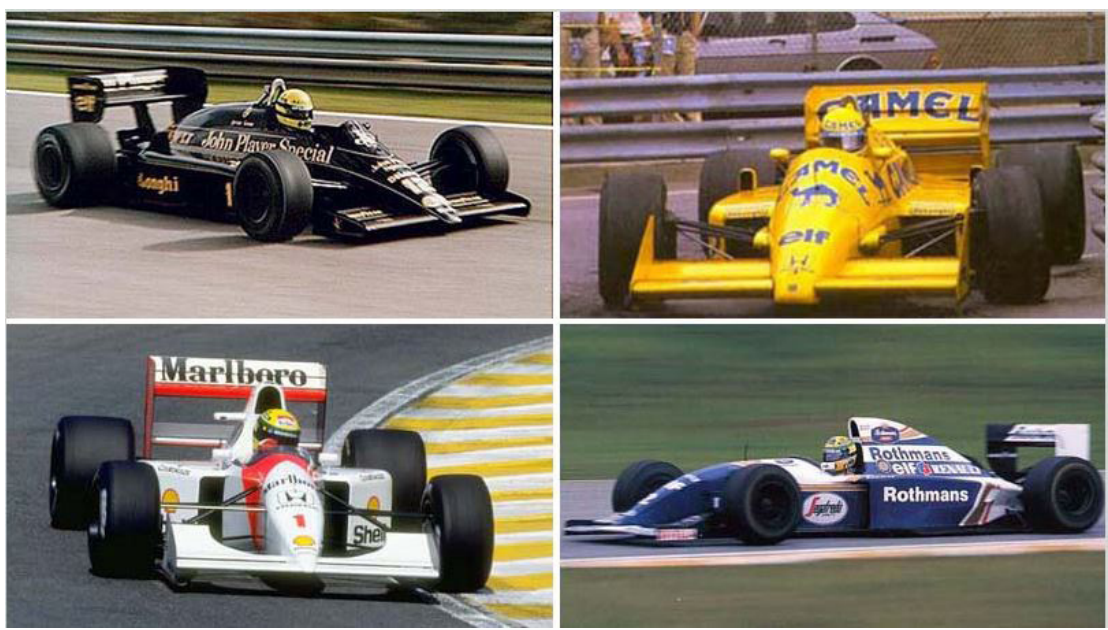

Fonte: Disponível em: <https://terceirotempo.uol.com.br/noticias/ayrton-senna-que-completaria59-anos-foi-garoto-propaganda-antes-mesmo-de-estrear-na-fl>.

No universo esportivo, os atletas que se destacam em sua modalidade são alçados à fama midiática. É impensável, na atualidade, um atleta de ponta que não desfrute dos benefícios financeiros gerados pelo uso de sua imagem. Ayrton Senna estampava a publicidade do tabaco nas pistas de corrida, mas também na mídia esportiva e no noticiário em geral. Com a transmissão das corridas e as notícias provenientes dos acontecimentos midiáticos da Fórmula 1, as imagens do esportista ganhavam 
uma potência discursiva nas diferentes capilaridades dos ambientes midiáticos. A capilaridade da comunicação é um conceito no qual os fenômenos comunicativos se esparramam ocupando espaços diversos, o que só foi possível com o aperfeiçoamento dos aparatos elétricos que não se desligam nunca e de suas linguagens cada vez mais rarefeitas; assim como o vento, as imagens se alastram por todas as frestas de forma efêmera e volátil (BAITELLO, 2010).

A escolha de Ayrton Senna como um dos garotos propagandas da indústria do cigarro não é aleatória. Senna é tido como um ídolo, com sucesso e fama. Como define o dicionário, ídolo é uma figura ou imagem que representa uma divindade objeto de adoração; um herói, digno de amor, respeito e admiração. Pensando a figura do herói midiático da atualidade, o ídolo vende. Ser uma "imagem” no universo publicitário corresponde a "vender", e vendas significam lucro para os anunciantes. Mesmo após a sua morte, a imagem "Ayrton Senna" ainda é atrelada a diversos produtos. Em 2019, 25 anos após a sua morte, a marca Senna já rendeu cerca US\$ 2 bilhões.

Pesquisa realizada em 201914, 25 anos após a sua morte, revela que Ayrton Senna figura entre as cinco celebridades com maiores notas em alguns atributos comportamentais e de influência como: humilde, confiável, admiração, tranquilo, multicultural, especialista em sua área, engajado em causas sociais e religioso. A essa lista podemos acrescentar atleta vitorioso, com grande sucesso financeiro e na carreira. Em praticamente todo o período em que foi piloto da Fórmula 1, mobilizou valores importantes atrelados à sua imagem para incentivar o tabagismo. Ao ser patrocinado pela indústria do tabaco, Ayrton Senna atuava como uma imagem. As marcas fundiam-se ao seu corpo, que operava como um "suporte midiático" (SANCHES, 2009). Em um cenário de alta exposição como a Fórmula 1, Senna emprestava seu corpo (e lucrava com isso) para as empresas que o patrocinavam, ganhavam visibilidade e também lucravam com as façanhas do piloto.

14 Disponível em <https://gazetaweb.globo.com/portal/noticia/2019/04/senna-ainda-e-um-dos-mais-influentes-entre-as-personalidades-nacionais_75750.php>. 


\section{Imagens patogênicas - as contribuições de Warburg para o estudo da imagem como pharmakon}

Retornando à questão: seriam as imagens patógenas? As imagens do arquivo de guerra de Aby Warburg não passaram incólumes ao olhar do pesquisador alemão. Elas tinham, como ele mesmo sabia, uma força inegável, um Pathosformel, ao mostrar o horror das batalhas e o sofrimento que seres da própria espécie podem provocar aos seus pares ou a outros seres, como os animais. As imagens do ídolo Ayrton Senna, promovendo e incentivando o consumo de cigarros, não são ingênuas e muito menos inofensivas: também elas são patogênicas e possuem a capacidade de impactar.

A indústria do tabaco (aqui, associada ao esporte) está ancorada em uma indústria das imagens. Sua força vem de uma potência das imagens tecnicamente pensadas e construídas, que abarcam rastros históricos e imagéticos e nos inserem em um ambiente construído culturalmente.

As imagens, como bem demonstrou Warburg, estão conectadas a uma historicidade pregressa e a uma potencialidade futura. Para pensar a imagem na atualidade é preciso refletir sobre a arqueologia dessa mesma imagem, os ambientes históricos e os cenários nos quais estão inseridas, além do seu impacto no momento presente e no futuro. As imagens oriundas do universo esportivo contemporâneo possuem uma historicidade - desde a pré-história, passando pelas competições medievais, os jogos olímpicos na Grécia, os mitos judaico-cristãos - o esporte leva o ser humano ao limite do seu corpo, uma obstinação contínua da humanidade pela superação e transcendência.

Sendo um "mosaico de elementos simbólicos" (LESSA, 2008, p. 6), o esporte, como uma atividade pré-histórica, está associado a uma série de outros elementos - um deles é o mito do herói - em um fenômeno descrito por Warburg como Bilderfahrzeug (veículos de imagens). O mito do herói está presente tanto no imaginário grego ou judaico quanto no ambiente esportivo (e em tantas outras esferas) do século XXI (o homem de negócios que faz com que uma empresa alcance lucros estratosféricos é também um herói). No conceito de Bilderfahrzeug, a 
potência das imagens através dos séculos não ocorre diligentemente ou de forma calculada, mas reside em sua capacidade de transportar símbolos. É daí que emerge a potencialidade divina e o impacto causado pelas imagens de atletas como Ayrton Senna. Cultuado no Brasil e no exterior, Senna é a personificação do herói, do ídolo (do grego eídōlon, que significa estátua, figura ou imagem de uma divindade, objeto de adoração). É ainda o arquétipo do lema olímpico "altius, citius, fortius" ou o "mais alto, o mais rápido, o mais forte" - máxima que pode ser atualizada e substituída por "mais visibilidade, mais patrocínio, mais dinheiro” (RUBIO, 2016, s/p). Não é à toa que, 25 anos após a sua morte, Senna continua sendo uma das personalidades brasileiras mais cultuadas e mercadologicamente lucrativas.

O mesmo raciocínio warburguiano está presente nas imagens que circulam em diferentes capilaridades e ambientes comunicacionais e tentam, a todo curso, impactar o sujeito contemporâneo. Ou seja, atuam como pharmakon, e podem ser patogênicas na medida em que incitam e promovem comportamentos nocivos à saúde física e mental. Não é à toa que Ayrton Senna estampava imagens de empresas de tabaco não apenas no carro de competição, mas também em seu corpo. A história do corpo é a história da civilização; logo, as imagens do corpo contam as histórias das civilizações, dos imaginários. A beleza estética do corpo está presente em praticamente toda a história da humanidade, do culto à nudez do paganismo ao Renascimento, inclusive nos corpos perfeitos e musculosos dos atletas da antiguidade e da atualidade. Os resquícios dos imaginários dos corpos reverberam através dos séculos e se fazem tão presentes hoje, seja no atleta ou no sujeito comum.

A coleção de imagens de guerra de Warburg e as guerras das imagens promovidas pela indústria do tabaco, são faces da mesma moeda. As imagens de guerra chocam pelo horror e pela aproximação com a morte e a destruição; já as guerras das imagens publicitárias atuam pela sedução, e podem levar a comportamentos e transtornos perigosos, como as diversas enfermidades malignas decorrentes do uso do tabaco. No exemplo da indústria tabagista, fica clara a patogenia das imagens. 
Mas as imagens como pharmakon estão presentes em outras ambiências midiáticas.

No caso específico de Senna, não estamos questionando sua capacidade ou índole como atleta ou ser humano, mas relatando um fato: como ídolo, portanto, como imagem, empregou seu corpo para disseminar e propagar o consumo de cigarro. Sua imagem transitava facilmente por diversas classes sociais, grupos étnicos e de diferentes idades. A força da imagem de Ayrton Senna (Pathosformel), sua capacidade de impacto e agir como propulsora de valores e comportamentos é inegável. Aqui, a imagem é patogênica quando induz ao consumo de cigarro, associado a um ídolo e tudo aquilo que ele representa. Lembrando que o ato de fumar não é inofensivo: $50 \%$ dos fumantes vão morrer por doenças relacionadas ao tabaco.

O caso Warburg pode nos oferecer subsídios para entendermos outras situações do uso da imagem como pharmakon. Além da já citada indústria do tabaco, podemos mobilizar os conceitos de Warburg para (re)pensar a eficácia e a força das imagens no estímulo à comportamentos nocivos à saúde física ou psicológica (ou ambas). Neste trabalho, apontamos para a possibilidade de ampliação das teorias e conceitos de Warburg para os estudos das imagens. As suas contribuições (sua teoria da imagem, sua ciência e seu método) podem emergir como expedientes poderosos para todos aqueles que pretendem pensar a imagem não pela sua raiz estetizante, mas como pharmakon. As contribuições de tais estudos podem ir além das ciências da comunicação e abranger principalmente as ciências cujo sujeito é afetado diretamente pelo impacto das imagens patogênicas, como a medicina (em especial a Psiquiatria) e a Psicologia. 


\section{Referências}

BAITELLO JR., N. A serpente, a mação e o holograma: Esboços para uma teoria da mídia. São Paulo: Paulus, 2010.

BAITELLO JR., N. Ideia vincit! Algumas imagens tangenciais à elipse de Warburg. Studies on the classical tradition. vol. 5, n. 1. p. 29-44, 2017.

BAITELLO JR., N. O pensamento sentado: Sobre glúteos, cadeiras e imagens. São Leopoldo: Editora Unisinos, 2012.

DALGALARRONDO, P. Psicopatologia e semiologia dos transtornos mentais. Porto Alegre: Artmed, 2008.

FICHTNER, G. Sigmund Freud - Ludwig Binswanger. Briefwechsel 1908-1938. Frankfurt/Main: Suhrkamp, 1992.

FILHO, C. M. (org.). Dicionário da Comunicação. São Paulo: Paulus, 2009

KLEIN, R. La forme et l'intelligible. Paris: Gallimard, 1970

LESCOURRET, M.A. Aby Warburg ou la tentation du regard: Biographie. Paris: Hazan, 2014.

LESSA, F. Esporte na grécia antiga: um balanço conceitual e historiográfico. Recorde: Revista de História do Esporte, v. 1, n. 2, dez. 2008.

MICHELETTI, M. J.. Ayrton Senna, que completaria 59 anos, foi garoto-propaganda antes mesmo de estrear na Fl. Blog $3^{\circ}$ Tempo. mar. 2019. Disponível em: <https:// terceirotempo.uol.com.br/noticias/ayrton-senna-que-completaria-59-anos-foi-garoto-propaganda-antes-mesmo-de-estrear-na-fl>. Acesso em 15 fev. 2020.

PORTER, R. Madness: A briefy history. New York: Oxford University Press, 2002.

SACKS, O. A mente assombrada. São Paulo: Companhia das Letras, 2013.

SACKS, O. Alucinações musicais. São Paulo: Companhia das Letras, 2007.

SACKS, O. O homem que confundiu sua mulher com um chapéu. São Paulo: Companhia das Letras, 1997.

SACKS, O. Vendo vozes. São Paulo: Companhia das Letras, 2010.

SANCHES, R. D. Do homem-placa ao pixman: O corpo como suporte midiático. São José do Rio Preto: Bluecom/FAPESP, 2009.

SERVA, L. Mnemosine da Primeira Guerra Mundial: Mapas para uma exposição de fotografias da coleção de Aby Warburg. Intercom. In: 40 Congresso Brasileiro de Ciências da Comunicação, Sociedade Brasileira de Estudos Interdisciplinares da Comunicação. Curitiba, Anais... Curitiba, 2017.

TETSURO, W. Antropología del paisaje: Climas, culturas y religiones. Salamanca: Sígueme, 2006.

THEISS-ABENDROTH, P. Die psychiatrische Behandlung des Aby Warburg: eine historische Kasuistik. In: Fortschrit. Neurol. Psychiatr. Stuttgart: Georg Thieme Verlag, 2010 .

WARBURG, A. Histórias de fantasma para gente grande: Escritos, esboços e conferências. São Paulo: Companhia das Letras, 2015.

WARBURG, A. Werke in einem Band. Auf der Grundlage der Manuskripte und Handexemplare. Ed. Martin Treml, Sigrid Weigel, Perdita Ladwig. Berlin: Suhrkamp, 2010. 
WARBURG, A.Fragmente zur Ausdruckskunde. Gesammelte Schriften Band IV. Berlin/ Boston: De Gruyter, 2015.

WARBURG, A.; BINSWANGER, L. La guérison infinie: Histoire clinique d'Aby Warburg. Paris: Bibliothèque Rivages, 2007.

\section{Sobre os autores}

Norval Baitello Jr. - Doutor em Ciências da Comunicação pela Universidade Livre de Berlim. Professor titular do Programa de Estudos Pós-Graduados em Comunicação e Semiótica da PUC-SP e Diretor Científico do Arquivo Vilém Flusser São Paulo e do CISC (Centro Interdisciplinar de Semiótica da Cultura e da Mídia). Pesquisador Pq 1A do CNPq. No presente artigo, o autor foi responsável pela definição da ideia original do estudo. Contribuiu com a escrita, hipótese, discussão, reflexões e, principalmente, pela vasta literatura sobre Aby Warburg, história e caso clínico. Também contribuiu e concordou com a revisão do texto.

Rodrigo Daniel Sanches - Pós-Doutorando em Comunicação pela Faculdade Cásper Líbero (FCL/SP). Doutor em Psicologia pela Faculdade de Filosofia, Ciências e Letras de Ribeirão Preto da Universidade de São Paulo (FFCLRP/ USP). Mestre em Comunicação e Semiótica (PUC/SP). Professor universitário na graduação (Centro Universitário Metropolitano de Campinas - Unimetrocamp) e pós-graduação lato sensu (Centro Universitário Belas Artes). No presente artigo, o autor contribuiu com a escrita, hipótese, discussão, reflexões e, principalmente, pela análise da indústria do tabaco, do caso Ayrton Senna e da literatura e discussão sobre o caso clínico de Warburg. Também contribuiu e concordou com a revisão do texto.

Data de submissão: 15/05/2020

Data de aceite: 03/1 1/2020 